\title{
Tuning the incorporation of magnesium into calcite during its crystallization from additive-free aqueous solution
}

Jacinta M. Xto ${ }^{1,2}$, Huachuan Du ${ }^{3}$, Camelia N. Borca ${ }^{1}$, Esther Amstad ${ }^{3}$, Jeroen A. van Bokhoven ${ }^{1,2}$ and Thomas Huthwelker ${ }^{1}$

${ }^{1}$ Paul Scherrer Institut, 5232 Villigen, Switzerland

${ }^{2}$ Institute for Chemical and Bioengineering, ETH Zürich, 8093 Zürich, Switzerland

${ }^{3}$ Soft Materials Laboratory, Institute of Materials, École Polytechnique Fédérale de Lausanne (EPFL), 1015 Lausanne,

Switzerland ${ }^{1}$ Paul Scherrer Institut, 5232 Villigen, Switzerland

\section{Thermodynamic calculations using Minteq}

Minteq calculations were done to simulate the experimental conditions in Table 1 . The $\mathrm{pH}$ sweep experiments were done between $\mathrm{pH} 6.0$ to $\mathrm{pH} 11.0$ with a step size of 0.5 using $\mathrm{Mg}: \mathrm{Ca}: \mathrm{CO}_{3}$ ratio of 5:1:2.5

as in table 1. To simulate thermodynamic equilibrium for carbonate effect and concentration effect, the values in table 1 were used as the input parameters for the calculations. All the experiments were done at $25^{\circ} \mathrm{C}$ and oversaturated solids were not allowed to precipitate. SIT method was used for activity corrections. The saturation index at equilibrium was determined based on the solubility constant (Ks) as included in the thermodynamic database of Minteq, after correction of temperature effects. The saturation index is simply the term log IAP - log Ks. A negative value implies under saturation (i.e. IAP is lower than the solubility constant) and the reverse is supersaturated i.e. a precipitate should form.

For the $\mathrm{pH}$ dependent carbonate speciation minteq calculations, $10 \mathrm{mM}$ sodium carbonate was used. Activity correction was done using Davies activity correction and b parameter of 0.3 was used. 24 steps were done for the $\mathrm{pH}$ sweep from a pH 2.0 to $\mathrm{pH} 13.5$. The calculations were done at 25 degrees and the ionic strength was determined during the calculations. To calculate the speciation of the activity of 
carbonate and bicarbonate ions at different $\mathrm{pH}$ values used during the actual $\mathrm{pH}$ experiment, the minteq simulation was done using the same $\mathrm{pH}$ sweep method but using a $0.25 \mathrm{M} \mathrm{Na}{ }_{2} \mathrm{CO}_{3}$ solution between $\mathrm{pH}$ 7.0 to $\mathrm{pH} 10.5$.

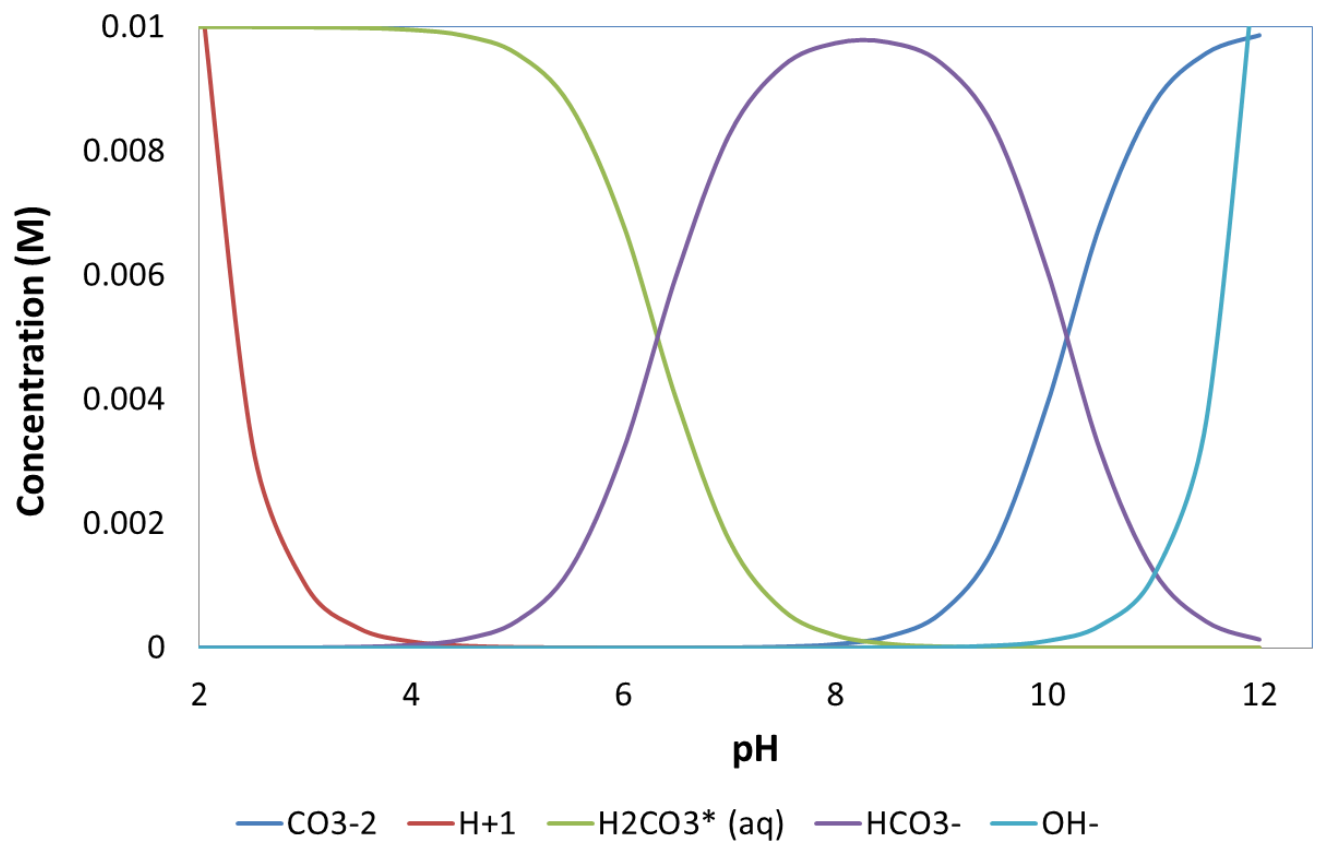

Figure S1: Minteq simulation for $\mathrm{CO}_{2} \mathrm{pH}$ dependent speciation in aqueous solution. 


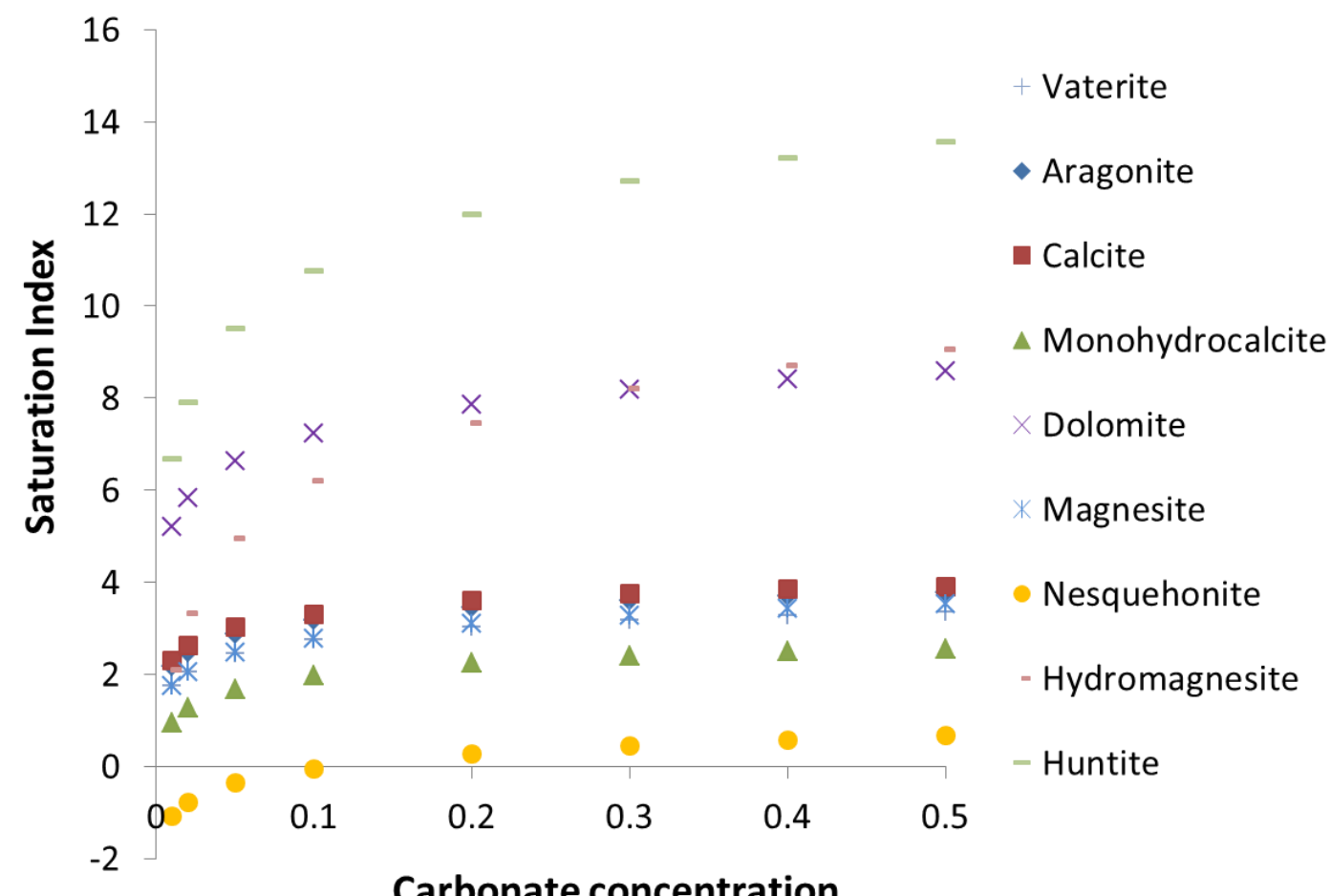

Figure S2: Calcium and magnesium carbonate mineral saturation index calculated by Minteq as a function of carbonate concentration at constant Magnesium: Calcium ratio of 5:1 


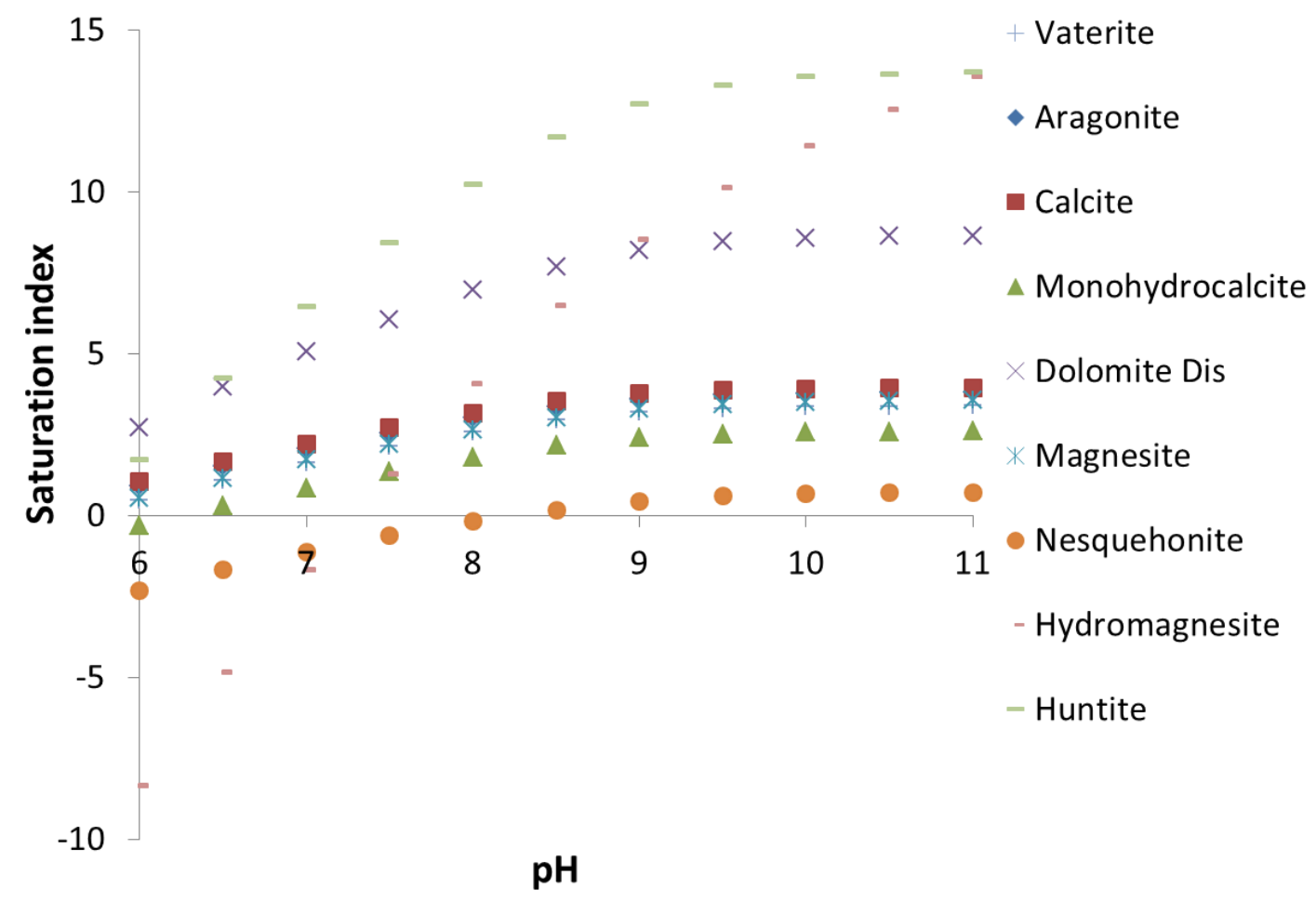

Figure S3: Calcium and magnesium carbonate mineral saturation index calculated by Minteq as a function of $\mathrm{pH}$ at a constant Magnesium: Calcium: Carbonate ratio of 5:1:2.5 


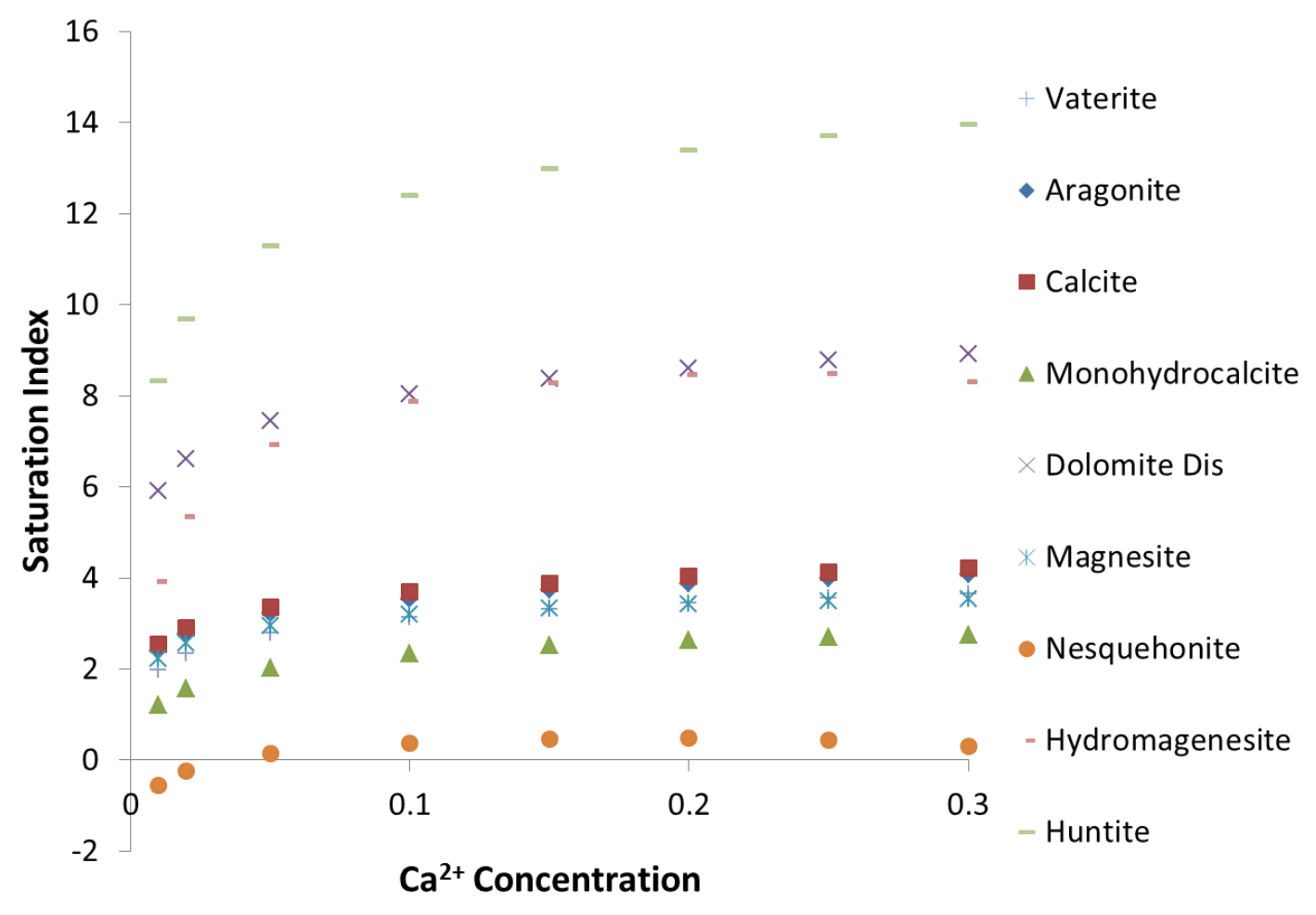

Figure S4: Calcium and magnesium carbonate mineral saturation index calculated by Minteq as a function of initial solution concentration at constant Magnesium: Calcium: Carbonate ratio of 5:1:2.5. 


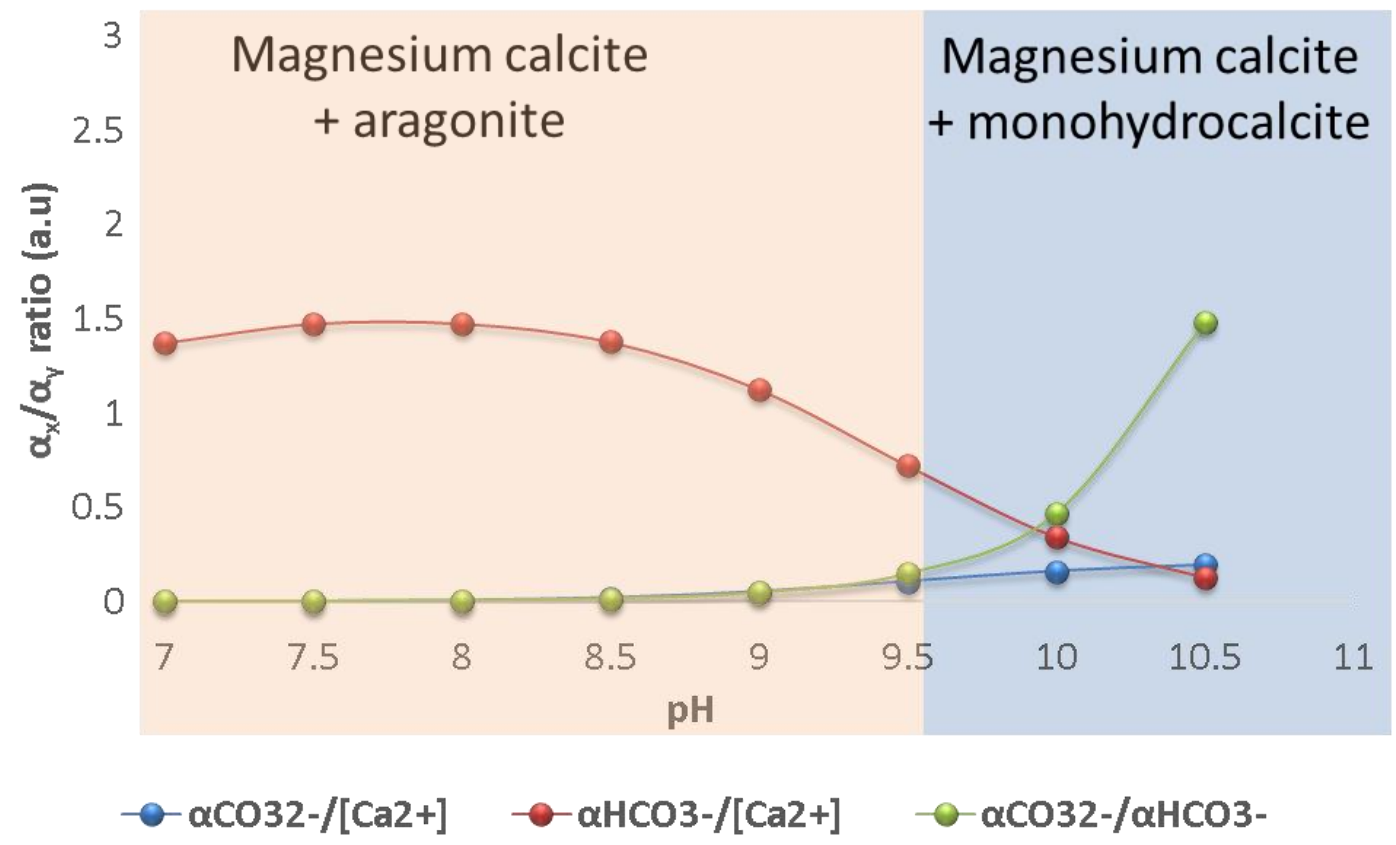

Figure S5: Minteq simulations of the ratio of experimental carbonate to calcium ions, bicarbonate to calcium ions and carbonate to bicarbonate ions as a function of $\mathrm{pH}$. 